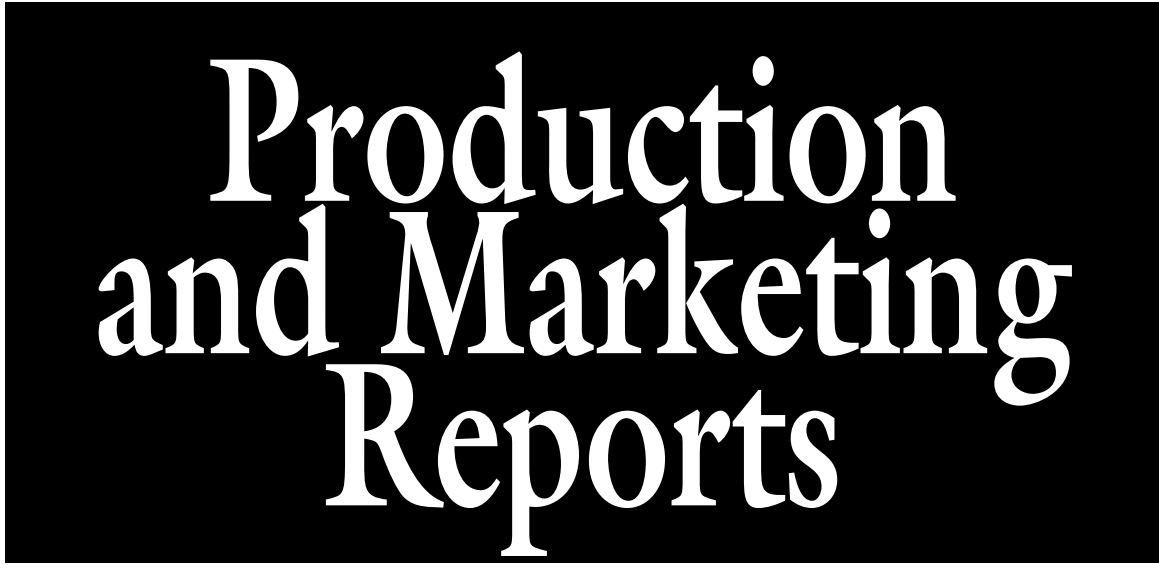

\title{
Evaluating the Business and Owner Characteristics Influencing the Adoption of Online Advertising Strategies in the Green Industry
}

\author{
Ariana P. Torres ${ }^{1,4,7}$, Susan S. Barton ${ }^{2,5}$, and Bridget K. Behe $e^{3,6}$
}

ADDITIONAL INDEX WORDs. Internet, online marketing, social media, website

Summary. As more individuals use the Internet for business and leisure, the opportunities for firms to promote products and services and to communicate with consumers online increases. The objective of this study was to investigate green industry managerial decisions to engage in online advertising and how much to invest while determining the main drivers contributing to these decisions. A doublehurdle model analyses of 1735 responses to the 2014 National Green Industry Survey, which gathered information on business practices, showed $>40 \%$ of green industry business invested in online advertising. Typically, businesses investing in online advertising spent more than $43 \%$ of all advertising expenditures in online methods, including websites, social media, and newsletters. Furthermore, the decision to engage in online advertising was driven by the percentage of wholesale and contract sales, market access, firm size, product mix, and business owners' perceptions. Results also showed that the amount of dollars invested in online advertising depended on firm size, tools used to find customers, location, and business owners' perceptions. Our findings can help extension personnel and policymakers with the design and deliver social media training and educational events. Our findings can also help green industry businesses understand the twostep nature of the decision to invest in online advertising.

$\mathrm{T}$ The U.S. environmental horticulture industry, or green industry, comprises production and wholesale nurseries and wholesale/ retail distribution centers, as well as marketing intermediaries (Hall et al., 2005 ). Although the green industry historically was one of the fastest growing sectors of the U.S. economy (Hall et al., 2005), Hall (2010) and Barton and Behe (2017) reported that some segments have become stagnant or declined. When industry markets decline, specialized industries that rely on niche markets often increase marketing expenditures to remain viable (Li et al., 2019). Palma et al. (2012) showed that most promotion and advertising expenditures were effective in increasing green industry sales. Six years later, Li et al. (2019) found the response function to be dependent on firm size with advertising expenditures increasing sales within a range of expenditures in small firms only. Yet managerial decisions regarding the decisions to invest in advertising, either conventional or electronic, have not been thoroughly investigated.

More people use technology in their daily lives, and therefore, technology-based marketing has become a more viable avenue for businesses to reach consumers. A recent study showed that $81 \%$ of American adults used the Internet; more than half of them were using two or more social media sites (Duggan et al., 2015). Nearly two-thirds of American adults use social media (Perrin, 2015). The Neilson Co. (2013) reported social networks and blogs were the top online destinations, accounting for most of the time online and reaching $80 \%$ or more of active Internet users. Additionally, consumers use multiple media simultaneously between $24 \%$ and $65 \%$ of the time they are using media (Foehr, 2006; Pilotta et al., 2004). Behe et al. (2013) showed that women were more likely to search online for both gardening and nongardening information, but men were more likely to make online gardening purchases. They also showed that having searched online for nongardening information increased the likelihood of an online purchase by $16 \%$.

Social media marketing is broadly defined as any online service through which users can create and share a variety of content. Although social media sites have existed since 1981, they were most widely adopted after 2003 (Boyd and Ellison, 2008). Americans born between 1980 and 1990, or Generation Y, use of social media is already changing the marketplace, workplace and society (Bolton et al., 2013). Interaction through social media sites is a way for organizations to build relationships (Waters et al., 2009), particularly among digital natives. Social media activity leads consumers to engage with other online formats such as businesses' websites, online purchases, and online newsletters (Pookulangara and Koesler, 2011). We defined online advertising as the allocation of resources to Internet-based advertising for promoting products and services through the Internet (Sridhar et al., 2016). Online advertising includes investments for websites, social media, e-newsletters, or paid advertisements.

The Internet has facilitated the growth of online advertising over the past decade, and online advertising has moved from being a peripheral to a central advertising medium because of its unique targeting capabilities (Doctorow et al., 2009). Reasonable costs and compatibility with traditional advertising have been important to increased online advertising in many industries (Peterson et al., 2018). Yet green industry firms struggle to integrate online advertising 
into their traditional advertising strategy (Danaher and Dagger, 2013).

Using online advertising strategies requires a change in traditional advertising processes (Burt and Sparks, 2003). First, business owners should integrate the use of computers and Internet in farm management, followed by adoption of online marketing tools such as advertisement of products and services through Facebook (Menlo Park, CA) and other social media. The 2017 Farm Computer Usage and Ownership report showed that more than $70 \%$ of U.S. farms had Internet access, but only $47 \%$ of the operations used it for farm business (U.S. Department of Agriculture, 2017). Given the tremendous potential influence of online marketing, several extension programs and industry conferences include the use of online tools in their training and educational efforts. For example, MS Bricks to Clicks was developed by extension specialists to train agricultural-based businesses on the adoption of online advertising activities (Barnes et al., 2014).

Some studies reported on the use of online tools in agricultural firms. Baer and Brown (2007) found while firm size increased the likelihood of website adoption for direct marketing, not all direct-market farms were interested in using the Internet as a marketing tool. Baer and Brown (2007) also found the number of advertising methods used, presence of high-speed Internet, and farm sales were positively related to

Received for publication 9 Jan. 2019. Accepted for publication 6 Mar. 2019

Published online 9 April 2019.

We thank the Horticultural Research Institute, which supplied funding essential for data collection. We also thank the members of the S-1065 Regional Project for the data, especially Dr. Alan Hodges, University of Florida, who led the survey data collection and data set verification efforts.

${ }^{1}$ Department of Horticulture \& Landscape Architecture and Agricultural Economics, Purdue University, 625 Agriculture Mall Drive, West Lafayette, IN 47907

${ }^{2}$ Department of Plant \& Soil Sciences, University of Delaware, 146 Townsend Hall, Newark, DE 19716

${ }^{3}$ Department of Horticulture, Michigan State University, 1066 Bogue Street, East Lansing, MI 48824

${ }^{4}$ Assistant Professor.

${ }^{5}$ Professor and Extension Specialist.

${ }^{6}$ Professor.

${ }^{7}$ Corresponding author. E-mail: torres2@purdue.edu.

This is an open access article distributed under the CC BY-NC-ND license (https://creativecommons.org/ licenses/by-nc-nd/4.0/).

https://doi.org/10.21273/HORTTECH04274-19 website adoption while having an onfarm stand or store, selling produce or baked goods, and renting some land were negatively related to website use. Small farmers surveyed in 2000 used the Internet as a promotional tool to advertise their products (Ball and Duval, 2001). They reported findings that firms spent on average $\$ 565$ for online direct marketing in 1997 with 65\% reporting their online advertising efforts were somewhat or very successful.

Despite the opportunities online marketing can bring to green industry operations, little is known about the drivers of adopting online advertising and how those factors influence the amount invested in online advertising. In the context of Internet adoption, most studies are relatively outdated, and new research on drivers of online advertising adopted among businesses is needed. Reinartz (1996) found that nurseries/garden centers and florists employed few interactive and content features on their websites, although this is a main strength of the Internet. Only a few studies published recently have focused on the online advertising tools used by green industry businesses. Huang and Chen (2018) investigated the use of Facebook posts by florists in Taiwan. They showed florists were increasingly adopting social media advertising to engage with customers by advertising products and expressing gratitude. Peterson et al. (2018) found that most business owners used Facebook (91.4\%) to engage with customers, followed by websites (81.5\%), e-newsletters (60.3\%), Twitter (San Francisco, CA) (29.8\%), and blogs (23.2\%). Most businesses advertising through these online tools used them once per week.

The aim of this article is to investigate the business and managerial characteristics that influence the decision to adopt online strategies among green industry firms. The objectives of this paper are to evaluate the business and owner characteristics most closely associated with investing in online advertising, and business and owner characteristics most closely associated with the amount invested in online advertising by green industry firms. We used a double-hurdle model to separate these decisions in two stages and estimate online advertising investing and the investmentassociated amount.

\section{Data and methodology}

The present study used the Hooker et al. (2001) definition of online marketing (electronic marketing or e-marketing) as the "strategic process of creating, distributing, promoting, and pricing goods and services to a target market over the Internet or through digital tools." Further, we defined online advertising as the allocation of resources to Internet-based advertising for promoting products and services through the Internet (Sridhar et al., 2016). Online advertising represents a set of powerful tools and methodologies used for promoting products and services through the Internet, such as paid online marketing, use of social media for consumer engagement, newsletters sent via e-mail, and searchengine marketing, among others (Strauss, 2016). Online advertising includes a wider range of marketing elements than traditional business marketing due to the additional channels and marketing mechanisms available on the Internet (Techopedia, 2018).

Data Description. We used data from the 2014 National Green Industry Survey that gathered information on business practices and operating results for calendar year 2013 or fiscal year 2013-14. That survey represented the sixth national survey conducted by the Green Industry Research Consortium (Hodges et al., 2015). The 2014 survey targeted green industry businesses for the first time with new questions added regarding digital marketing practices. The questionnaire and survey protocol were approved by the University of Florida Institutional Review Board for compliance with ethical standards for human subjects research. The survey targeted 32,000 firms, including 15,000 grower or grower/dealer firms randomly selected to receive the questionnaire mailed via the U.S. Postal Service, and all 17,000 firms with e-mail addresses received the survey via e-mail (Internet). Methods used to draw the sample and survey protocol procedures are described in detail in Hodges et al. (2015).

Valid responses were received from 2657 firms, including 1712 (64\%) from the mail survey and 945 (36\%) from the e-mail survey. A total of $299(2.0 \%)$ of mailed surveys were returned as undeliverable, and 958 
e-mail addresses were considered undeliverable. In addition, 377 firms refused to participate ("opted out") of the e-mail survey. After deducting the undeliverable and noncompliant firms, the overall response rate for the survey was $\approx 8 \%$. A summary of general findings from the study is found in Hodges et al. (2015). A means comparison test showed no difference between main and online survey; thus, we combined the answers from both surveys.

From the 2657 responses, we drew a subsample of 1215 commercial growers. We defined commercial operations as those that reported $\$ 10,000$ or more in sales in 2013. We excluded businesses that reported annual sales lower than $\$ 10,000$, representing operations that were not participating in the business full-time. The questionnaire asked businesses to report the amount of advertising expenditures as percentage of annual sales. When looking into the type of advertising expenditures, we found that of 1215 growers, $488(40 \%)$ invested in online advertising, and $727(60 \%)$ did not. Figure 1 illustrates the distribution of the percentage of online advertising among those investing in online strategies. Of those investing in online advertising, the average percentage of online advertising as a share of all advertising expenditures was $46 \%$, whereas the median was $40 \%$. Online advertising expenditures included expenditures on Internet, social media, and e-newsletter advertising. Of 1215 businesses, $448(25 \%)$ were growers selling wholesale and 767 (44\%) were growers selling wholesale/retail. Thus, we further categorized growers as wholesale (if the business sold most of plant material to wholesalers) and wholesale/retail (if the business sold plant material through both wholesale and retail).

E M P I R I C A L M O D E L SPECIFICATION. In this section, we discuss the method employed in estimating 1) the factors influencing investing in online advertising and 2 ) the factors influencing the amount invested in online advertising. We conducted all analyses using Stata (release 14; StataCorp, College Station, TX). We used a double-hurdle model to separate these decisions in two stages and estimate online advertising investing and the investment-associated amount. The double-hurdle model, an extension on the standard Tobit model, relaxes the Tobit assumption that the factors affecting the decision to invest in online advertising (step l) have the same effect on the amount invested (step 2). In other words, the doublehurdle model estimates what drives green industry business owners to first determine whether they want to invest in online advertising (the participation decision), then decide on an optimal investment in online advertising (the quantity decision). Aramyan et al. (2007) and Detre et al. (2011) used a similar model to decouple investment

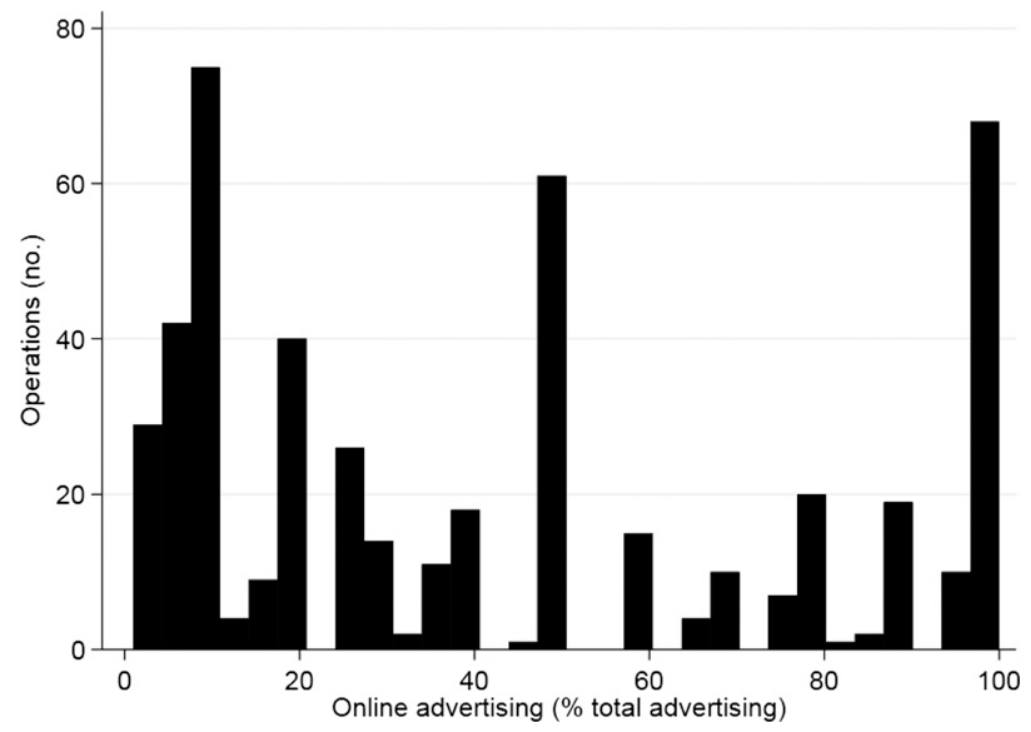

Fig. 1. Number of green industry operations participating in a national survey and their investment in online advertising investment as a proportion of total advertising expenditures. from the amount of investment among agricultural firms.

The model is given by Eq. [1], which illustrates the two-step process from the first to the second stage, where business owners "hurdle" to the second stage if they invested in online advertising (given $y_{1}=1$ ):

$$
\begin{aligned}
f\left(y_{2} \mid x\right) & \\
\quad & \begin{cases}\operatorname{Pr}\left[y_{1}=0 \mid x\right] & \text { if } y_{2}=0 \\
\operatorname{Pr}\left[y_{1}=1 \mid x\right] f\left(y_{2} \mid y_{1}=1, x\right) & \text { if } y_{2}=1\end{cases}
\end{aligned}
$$

We followed Duan et al. (1983) and Cameron and Trivedi (2009) to define the first decision as a probit regression by Eq. [2] and the second decision as a least-square regression by Eq. [3]. Eq. [2] is a normally distributed probability regression, where $y_{1}$ is equal to 1 if the business invested in online advertising, and $y_{1}$ is equal to zero otherwise; and $x$ is the vector of business owner and business characteristics discussed subsequently. Eq. [3] used a continuous value of the percentage of online advertising $\left(y_{2}\right)$ as a proportion of all advertising expenditures. The variable $y_{2}$ is observed only if $y_{1}=1$. Eq. [3] used an ordinary least squares regression for the percentage of online advertising invested, given that the business invested in online advertising, where $x$ is the vector of explanatory variables used in Eq. [2] and $v$ is the error term.

$$
\begin{aligned}
& \operatorname{Pr}\left(y_{1}=1 \mid x\right)=\phi\left(x^{\prime} \beta\right) \\
& \left(y_{2} \mid y_{1}=1, x\right)=x^{\prime} \beta+v
\end{aligned}
$$

Table 1 describes the set of explanatory variables $x$ used in Eqs. [2] and [3], and Table 2 provides the descriptive statistics of all the variables used in the model, which includes the percentage of online advertising, business characteristics, product offering, geographic characteristics, and business owners' perceptions. Business characteristics included business size (annual sales), number of employees, years of operation, marketing expenditures, and marketing strategies. Product offerings included container, balled or burlapped, field-grown bag, bare root, in-ground container, pot-inpot, and other plant forms. Businesses were segregated in eight U.S. geographic regions: Appalachian, Great Plains, Midwest, Mountain, Northeast, Pacific, South-central, and Southeast. 
Table 1. Categories and descriptions of the variables used to investigate the drivers of investing in online advertising among green industry growers.

\begin{tabular}{|c|c|}
\hline Variable & Description \\
\hline Online advertising (\%) & $\begin{array}{l}\text { Percentage of online advertising via Internet or social media } \\
\text { as percentage of advertising expenditures }\end{array}$ \\
\hline Sales in contracts $(\%)$ & Percentage of sales through contracts \\
\hline Wholesale sales $(\%)$ & Percentage of sales via wholesale \\
\hline $\begin{array}{l}\text { Market diversification } \\
\text { index }\end{array}$ & $\begin{array}{l}\text { Diversification index (measured with the Herfindahl index) } \\
\text { for number of sales methods denoting the number of } \\
\text { methods used to sell products, including trade shows, } \\
\text { telephone, in person, mail, and Internet }\end{array}$ \\
\hline $\begin{array}{l}\text { Market distribution } \\
\text { index }\end{array}$ & $\begin{array}{l}\text { Diversification index (measured with the Herfindahl index) } \\
\text { for distribution sales methods, denoting the percentage } \\
\text { sales through each method }\end{array}$ \\
\hline Trade shows (no.) & Number of tradeshows attended in 2013 \\
\hline (no.) & Number of employees \\
\hline Small $(\%)$ & $1=$ if annual gross sales were $<\$ 250,000$ \\
\hline Medium (\%) & $\begin{aligned} 1 & =\text { if annual gross sales were between } \$ 250,000 \text { and } \\
& <\$ 1,000,000\end{aligned}$ \\
\hline Large $(\%)$ & $1=$ if annual gross sales were $\geq \$ 1,000,000$ (reference group) \\
\hline Time operating (years) & Years of operation \\
\hline Time operating $\left(\right.$ years $\left.^{2}\right)$ & Square of years of operation \\
\hline Online demographic (\%) & $\begin{array}{l}1=\text { if business used the Internet or social media as a method } \\
\text { to obtain customer demographics }\end{array}$ \\
\hline Appalachian (\%) & $1=$ if business is located in the Appalachian region \\
\hline Great plains (\%) & $1=$ if business is located in the Great Plains region \\
\hline Midwest (\%) & $1=$ if business is located in the Midwest region \\
\hline Mountain (\%) & $1=$ if business is located in the Mountain region \\
\hline Northeast (\%) & $\begin{array}{l}1=\text { if business is located in the Northeast region (reference } \\
\text { group) }\end{array}$ \\
\hline Pacifi & $1=$ if business is located in the Pacific region \\
\hline Soutl & $1=$ if business is located in the Southcentral region \\
\hline Southeast (\%) & $1=$ if business is located in the Southeast region \\
\hline Conta & $\begin{array}{l}\text { Percentage sales from containerized products (reference } \\
\text { group) }\end{array}$ \\
\hline Burlappe & Percentage sales from balled/burlapped \\
\hline Field- & Percentage sales from Field-g \\
\hline Bare $\operatorname{root}(\%)$ & Percentage sales from bare root \\
\hline Ball-potted (\%) & Percentage sales from in-ground con \\
\hline Pot-in-pot $(\%)$ & Percentage sales from pot-in-pot \\
\hline Other form $(\%)$ & Percentage sales from other forms \\
\hline Barrier hire (\%) & $\begin{array}{l}\mathrm{l}=\text { if hiring competent labor is an important factor affecting } \\
\text { business growth }\end{array}$ \\
\hline Barrier demand $(\%)$ & $\begin{array}{l}1=\text { if market demand is an important factor affecting } \\
\text { business growth }\end{array}$ \\
\hline Barrier competition (\%) & $\begin{array}{l}1=\text { if competition is an important factor affecting business } \\
\text { growth }\end{array}$ \\
\hline Market geographic (\%) & $\begin{array}{l}1 \text { = if marketing is an important factor affecting the } \\
\text { geographic range of business }\end{array}$ \\
\hline $\begin{array}{l}\text { Plants offering } \\
\text { geographic }(\%)\end{array}$ & $\begin{array}{l}1=\text { if plant offerings is an important factor affecting the } \\
\text { geographic range of business }\end{array}$ \\
\hline $\begin{array}{l}\text { Transportation } \\
\text { geographic (\%) }\end{array}$ & $\begin{array}{l}1=\text { if transportation is an important factor affecting the } \\
\text { geographic range of business }\end{array}$ \\
\hline
\end{tabular}

We were interested to understand how managerial decisions regarding market diversification may affect online advertising adoption. We measured the managerial ability of business owners to diversify across markets by using the Herfindahl index.
We followed Gollop and Monahan (1991) to decompose the sales diversification strategies of green industry businesses into two components: number of sales methods used (first bracket) and distribution of sales per method (second bracket):

$$
\begin{aligned}
\text { diversification }= & 1-\frac{1}{\text { methods }} \\
& +\sum_{i}\left[\frac{1}{\text { methods }^{2}}-\operatorname{share~}_{i}^{2}\right]
\end{aligned}
$$

The first bracket in Eq. [4] accounted for the number of sales methods used by businesses, including trade shows, telephone, in-person, mail, and Internet and reflects the number of different methods of sales (market diversification index) used by businesses. The market diversification index increases as the number of methods of sales used increases. For example, a business using five methods would have a value of 0.8 for the first bracket, while an operation selling only in-person (one method) would have a value of zero. A higher number of selling methods used indicates a higher degree of market diversification.

The second bracket in Eq. [4] reflects the diversification in distribution of sales methods (market distribution index), which accounts for the proportion of sales through each of the different sales methods. For example, a business that reported selling two products and an equal proportion $(50 / 50)$ of in-person and trade shows sales would have a distribution component of -0.25 , or $\frac{1}{2^{2}}-\left(0.5^{2}+0.5^{2}\right)=-0.25$. In the other hand, a business selling 90\% products in-person and only $10 \%$ via trade shows would have a diversification component of $\frac{1}{2^{2}}-\left(0.9^{2}+0.1^{2}\right)=$ -0.57 . In other words, larger negative values of the diversification component would indicate more unequal distribution of sales.

\section{Empirical results Summary statistics}

Table 2 illustrates the mean differences for all the variables used in the model, by type of main market channel. The average green industry grower invested $17 \%$ of all advertising expenditures on online strategies, including Internet and social media advertising. The investment on online advertising was higher among business that had wholesale/retail sales compared with those firms selling mainly through wholesale markets $(P<0.05)$. Growers reported, on 
Table 2. Comparison of respondents of the 2014 National Green Industry Survey of green industry growers in the United States $(\mathrm{N}=1215)$ categorized by market outlets as wholesale $(N=448)$ or wholesale/retail $(N=767)$. Values represent the percentage of businesses with each of the attributes.

\begin{tabular}{|c|c|c|c|}
\hline$\underline{\text { Business attribute }}$ & Full sample & Wholesale & Wholesale/retail \\
\hline Online advertising (\%) & 17.31 & $11.72 \mathrm{~b}^{\mathrm{y}}$ & $20.57 \mathrm{a}$ \\
\hline Sales in contracts $(\%)^{\mathrm{z}}$ & 12.42 & $17.04 \mathrm{a}$ & $9.72 \mathrm{~b}$ \\
\hline Wholesale sales $(\%)^{\mathrm{z}}$ & 64.12 & $98.44 \mathrm{a}$ & $44.08 \mathrm{~b}$ \\
\hline Market diversification index & 0.32 & 0.35 & 0.30 \\
\hline Market distribution index & -0.23 & -0.24 & -0.22 \\
\hline Trade shows (no.) & 1.05 & $1.32 \mathrm{a}$ & $0.88 \mathrm{~b}$ \\
\hline Employees (no.) & 24.29 & $42.83 \mathrm{a}$ & $13.30 \mathrm{~b}$ \\
\hline Small $(\%)^{\mathrm{z}}$ & 55.97 & $45.76 \mathrm{~b}$ & $61.93 \mathrm{a}$ \\
\hline $\operatorname{Medium}(\%)^{\mathrm{z}}$ & 22.22 & 25.22 & 20.47 \\
\hline Large $(\%)^{\mathrm{z}}$ & 21.81 & $29.02 \mathrm{a}$ & $17.60 \mathrm{~b}$ \\
\hline Time operating (years) & 28.99 & 28.68 & 29.17 \\
\hline Time operating $\left(\right.$ years $\left.^{2}\right)$ & $1,325.97$ & $1,231.02$ & $1,382.09$ \\
\hline Online demographic ${ }^{z}$ & 23.05 & $14.51 \mathrm{~b}$ & $28.03 \mathrm{a}$ \\
\hline Appalachian $(\%)^{\mathrm{z}}$ & 15.31 & 15.40 & 15.25 \\
\hline Great Plains $(\%)^{\mathrm{z}}$ & 2.14 & $0.45 \mathrm{~b}$ & $3.13 \mathrm{a}$ \\
\hline Midwest $(\%)^{\mathrm{z}}$ & 14.73 & 12.05 & 16.30 \\
\hline Mountain $(\%)^{\mathrm{z}}$ & 3.29 & 3.35 & 3.26 \\
\hline Northeast $(\%)^{\mathrm{z}}$ & 24.20 & $17.41 \mathrm{~b}$ & $28.16 \mathrm{a}$ \\
\hline Pacific $(\%)^{\mathrm{z}}$ & 8.15 & 7.59 & 8.47 \\
\hline Southcentral $(\%)^{\mathrm{z}}$ & 8.48 & $9.38 \mathrm{a}$ & $7.95 \mathrm{~b}$ \\
\hline Southeast $(\%)^{\mathrm{z}}$ & 23.70 & $34.38 \mathrm{a}$ & $17.47 \mathrm{~b}$ \\
\hline Container $(\%)^{\mathrm{z}}$ & 82.11 & 82.95 & 81.68 \\
\hline Burlapped $(\%)^{\mathrm{z}}$ & 14.33 & $19.90 \mathrm{a}$ & $11.07 \mathrm{~b}$ \\
\hline Field-grown $\left(\%^{\mathrm{z}}\right)$ & 0.51 & 0.36 & 0.60 \\
\hline Bare $\operatorname{root}(\%)^{\mathrm{z}}$ & 4.98 & 3.84 & 5.65 \\
\hline Ball-potted $(\%)^{z}$ & 0.78 & 0.61 & 0.88 \\
\hline Pot-in-pot $(\%)^{z}$ & 1.86 & 1.64 & 1.98 \\
\hline Other form $\left(\%^{\mathrm{z}}\right)$ & 9.53 & 9.88 & 9.32 \\
\hline Barrier hire $(\%)^{\mathrm{z}}$ & 36.05 & 39.06 & 34.29 \\
\hline Barrier demand $(\%)^{\mathrm{z}}$ & 85.35 & 85.04 & 85.53 \\
\hline Barrier competition $(\%)^{\mathrm{z}}$ & 52.51 & 55.80 & 50.59 \\
\hline Market geographic $(\%)^{\mathrm{z}}$ & 40.00 & 37.95 & 41.20 \\
\hline Plants offering geographic $(\%)^{\mathrm{z}}$ & 57.45 & 54.46 & 59.19 \\
\hline Transportation geographic $(\%)^{\mathrm{z}}$ & 62.06 & 64.73 & 60.50 \\
\hline
\end{tabular}

${ }^{\mathrm{z}}$ Mean percentage of businesses with that attribute.

${ }^{y}$ Lower case letters show statistically significant differences across columns at $P<0.05$ using Tukey's significant difference test.

average, $12 \%$ of their sales were via contracts. As expected, the amount of sales by contract was higher among businesses selling to wholesalers compared with those selling through wholesale/retail $(P<0.05)$.

On average, green industry employees attended one trade show in 2013 , and the number of these events was higher for wholesale growers than for those selling through wholesale/ retail outlets $(P<0.05)$. Over $55 \%$ of businesses in our sample were small (annual sales $<\$ 125,000$ ), and the proportion of small businesses was higher among wholesale/retail $(P<$ $0.05)$. Table 2 shows the average number of employees in each of the responding businesses was 24 . The number of employees for wholesale growers was higher (43 employees) than for wholesale/retail growers (13 employees) $(P<0.05)$.

The average green industry business reported 29 years of operation. Approximately $23 \%$ of businesses used the Internet and social media as methods to obtain customers demographics, and the use of these tools was higher for businesses selling through wholesale/retail channels $(P<0.05)$. Most of operations in our sample were in the Northeast (24\%) and Southeast (24\%), followed by Appalachian (15\%), Midwest (15\%), South-central (9\%), Pacific (8\%), Mountain (3\%), and Great Plains regions (2\%) of the United States. There was a higher percentage of growers selling through wholesale/retail in the Great Plains and Northeast regions, whereas most of the wholesale grower operations were in the Southeast and Southcentral regions $(P<0.05)$.

Businesses in our sample reported a higher percentage of sales of container plants $(82 \%)$, followed by balled and burlapped [B\&B (14\%)], and other forms of plant material $(10 \%)$. Although there were small differences across business type, similar percentages of plant material sales were observed across wholesale and retail growers for field-grown, ballpotted, pot-in-pot, and other forms of plant material sold. The product difference across grower types was the sales of $B \& B$ plant material, which was higher for wholesale growers than for wholesale/retail growers $(P<$ $0.05)$. Main barriers for business growth cited by business owners were market demand ( $85 \%$ of firms) and competition (53\% of firms). Most growers in our sample reported transportation (62\% of firms) and plant offerings (58\% of firms) as major factors affecting the geographic range of business.

\section{Regression results}

This section presents the results of the two questions to be answered about the investment on online advertising among green industry businesses. The results of the two questions can be found in Table 3 .

WHAT DRIVES GREEN INDUSTRY BUSINESSES TO INVEST IN ONLINE ADVERTISING? The first stage of the double-hurdle model investigated whether the business invested in online advertising. The results indicate that sales method was a major factor influencing the adoption of online advertising. Increasing sales via contracts $(P<0.05)$ and increasing the amount of wholesale sales $(P<0.01)$ decreased the probability of investing in online advertising among green industry businesses. It seemed that businesses selling larger volume to wholesalers and via contracts perceived that online advertising may not be an effective strategy to reach their customers. This may be due to a smaller number of customers because wholesale sales and contracts may be indicative of larger volume customers.

Increasing the number of market channels $(P<0.01)$ and the sales 
Table 3. Double-hurdle results of the drivers of investment in online advertising and the drivers of the amount invested in online advertising among green industry growers in the United States.

\begin{tabular}{|c|c|c|c|c|}
\hline \multirow[b]{2}{*}{ Variable } & \multicolumn{2}{|c|}{$\begin{array}{c}\text { Drivers of investment on } \\
\text { e-advertising } \\
\end{array}$} & \multicolumn{2}{|c|}{$\begin{array}{l}\text { Drivers of the amount } \\
\text { invested on e-advertising }\end{array}$} \\
\hline & Coefficient & $\mathrm{SE}$ & Coefficient & SE \\
\hline Percentage sales in contracts & -0.01 & $0.01 * *$ & 0.24 & 0.15 \\
\hline Percentage wholesale & -0.01 & $0.01 * * *$ & 0.24 & $0.11 * *$ \\
\hline Market diversification index & 1.15 & $0.25 * * *$ & -20.11 & 19.34 \\
\hline Market distribution index & 0.49 & $0.25 * *$ & -11.84 & 21.39 \\
\hline Number of trade shows & 0.03 & 0.03 & -4.99 & $2.15 * *$ \\
\hline Number of employees & -0.01 & 0.01 & -0.03 & 0.06 \\
\hline Small & -0.60 & $0.13 * * *$ & 39.34 & $11.08 * * *$ \\
\hline Medium & -0.17 & 0.13 & 5.30 & 10.57 \\
\hline Years operating & -0.01 & 0.01 & -0.52 & 0.38 \\
\hline Years $^{2}$ operating & 0.01 & 0.01 & 0.01 & 0.01 \\
\hline Online demographic & 0.65 & $0.11 * * *$ & 31.13 & $7.82 * * *$ \\
\hline Appalachian & 0.07 & 0.15 & -13.81 & 14.81 \\
\hline Great plains & -0.33 & 0.28 & -82.75 & 56.37 \\
\hline Midwest & 0.17 & 0.15 & 13.57 & 12.04 \\
\hline Mountain & -0.01 & 0.26 & 18.27 & 17.69 \\
\hline Pacific & -0.10 & 0.18 & 35.28 & $14.76 * *$ \\
\hline South-central & -0.16 & 0.18 & 24.03 & $13.17 *$ \\
\hline Southeast & 0.03 & 0.14 & 35.29 & $11.47 * * *$ \\
\hline Burlapped & 0.01 & 0.01 & 0.00 & 0.15 \\
\hline Field-grown & 0.01 & 0.01 & -0.73 & 0.97 \\
\hline Bare root & 0.01 & 0.01 & 0.15 & 0.16 \\
\hline Ball-potted & -0.01 & 0.01 & 0.89 & 0.59 \\
\hline Pot-in-pot & 0.01 & $0.01 * *$ & -0.13 & 0.32 \\
\hline Other form & 0.01 & $0.01 * * *$ & 0.00 & 0.12 \\
\hline Barrier hire & -0.02 & 0.10 & -1.56 & 7.53 \\
\hline Barrier demand & 0.01 & 0.16 & 26.09 & $13.31 * *$ \\
\hline Barrier competition & -0.07 & 0.09 & -19.07 & $6.92 * * *$ \\
\hline Market geographic & 0.34 & $0.10 * * *$ & -2.03 & 7.79 \\
\hline Plants offering geographic & 0.14 & 0.10 & -16.19 & $8.00 * *$ \\
\hline Transportation geographic & 0.04 & 0.10 & -7.82 & 8.01 \\
\hline Intercept & 0.12 & 0.25 & -23.31 & 22.95 \\
\hline Observations (no.) & & 980 & & \\
\hline Chi-square $P$ value & & 0.00 & & \\
\hline Sigma & & $45.29 * * *$ & & \\
\hline
\end{tabular}

$*, * *, * * *$ Significant at $P \leq 0.1,0.05$, or 0.01 , respectively.

distribution among those channels $(P<0.05)$ significantly increased the probability of green industry businesses investing in online advertising. Social media can help businesses build relationships, advertise products/ services, and increase sales. Ball and Duval (2001) found having an online presence (i.e., using online advertising) had a positive impact on the sales of farming operations. We expected that in an effort to diversify markets, business owners found online advertising useful to reach a wider range and larger number of customers.

The result that small businesses were less likely to invest in online advertising $(P<0.01)$ was somewhat intuitive. Baer and Brown (2007) reported a similar result in that larger
Businesses growing and selling plants in pot-in-pot containers were more likely to invest in online advertising $(P<0.05)$, which may indicate a linkage between using this newer mode of containerized plant production and more innovation in advertising strategies. Lastly, business owners perceiving that marketing was an important factor affecting the geographic range of business were more likely to invest in online advertising $(P<0.01)$. Business owners aware of the power of marketing can value online advertising to draw customers from other areas.

HOW MUCH DID THE BUSINESS INVEST IN ONLINE ADVERTISING? Small businesses were less likely to invest in online advertising compared with larger businesses. However, once they did so, the percentage of investment was higher compared with their larger counterparts $(P<0.01)$. This result implies that small businesses are less likely to invest in online advertising, maybe due to resource and time availability, but when they invest, they tend to dedicate a larger percentage of advertising to online methods compared with larger businesses.

Table 3 shows that businesses with a larger percentage of wholesale sales invest more in online advertising $(P<0.05)$. An explanation may be that small wholesalers are less likely to invest in online advertising as a group, but those innovative businesses that do tend to invest a lot in social media, e-newsletters, and websites. Increasing the number of trade shows a firm attended decreased their investment in online advertising $(P<0.05)$. Trade shows may be a way for growers to establish and maintain more personal, face-to-face relationships with current and potential buyers. Developing these direct relationships may deter business owners from engaging in online marketing as a strategy to find new ways to engage with those buyers.

Businesses located in the Pacific, South-central, and Southeast regions of the United States invested a higher percentage of their advertisement budget in online advertising compared with firms located in the Northeast $(P<0.01)$. Larger population centers and greater distance to market may be encouraging businesses located in these regions to engage with customers and build brand awareness via online advertising. Together 
these findings show the characteristics that drive and deter green industry growers to invest in online advertising are different from those that ultimately increase the investment in online advertising. Only one factor increased both the probability of investment in online advertising and the amount invested in online advertising: the use of online methods to find customers demographics $(P<0.01)$.

\section{Conclusions and implications}

Businesses in markets facing maturity have seen the return on investment that advertising can bring (Palma et al., 2012), and green industry firms are no exception. Although most promotion and advertising is effective for green industry businesses (Palma et al., 2012), online advertising seems to be most impactful for smaller sales firms ( $\mathrm{Li}$ et al., 2019). To advance the literature, this study sought to identify the business and owner characteristics associated with investing in online advertising and driving the amount of investment. These two decisions are important to businesses as they seek newer means to connect with consumers who use the Internet increasingly more for personal and professional communications. This was noted in the finding that business owners who perceived that marketing was an important factor affecting the geographic range of the firm were more likely to invest in online advertising. It seems that findings from Ball and Duval (2001), in which most business owners perceived that online marketing efforts were somewhat or very successful, has continued today.

Selling a large percentage of plants at wholesale and via contracts likely limits the number of customers a production facility serves, and we observed these attributes reduced the probability of that firm engaging in online advertising. Yet these companies could enhance their face-to-face communications (e.g., trade-show attendance) and build brand awareness with end users through online advertising. Regardless of size or market outlets, social media advertising can help green industry firms build an online presence and educate and build a positive community with customers (Peterson et al., 2018).

Because results showed that smaller firms were less likely to adopt online marketing strategies to expand their reach, perhaps more resources, including employee expertise, could entice smaller firms to consider online advertising. However, it seems that smaller firms may be more likely to benefit the most from online marketing than larger operations (Yao et al., 2018). More programs such as Mississippi Bricks to Clicks (Barnes et al., 2014) that bring hands-on strategies for business owners could facilitate skill acquisition and adoption of online advertising. Education programs that provide information to growers on how to segment markets and understand their demographic characteristics can have a major impact on both the decision to invest and increase the amount of investment.

One of the major contributions of this article is the empirical evidence of the business characteristics and growers' attitudes influencing the adoption and level of adoption of online advertising in the green industry. One possible limitation of the study is the fact that the sample used in the study did not include plant retailers and firms engaged in landscaping services that are not plant growers and that the data were collected 5 years ago. New data available in 2019 will enable us to address these questions via a time series comparison. Future research should look at the decision of the entire green industry to invest in online advertising.

Future research should investigate the connection between investing in online advertising and leveraging the technology knowledge to the next sequential step: adopting online sales. We would expect that engaging in online advertising would decrease the technological barriers to start online direct sales. Given that Ball and Duval (2001) found having an online presence (i.e., using online advertising) increased the sales of farming operations, a next step would be to investigate the decision to sell horticultural products online and conduct another double-hurdle model to investigate the effect of online advertising on the adoption and amount of online sales in the green industry.

\section{Literature cited}

Aramyan, L.H., A.G.O. Lansink, and J.A. Verstegen. 2007. Factors underlying the investment decision in energy-saving systems in Dutch horticulture. Agr. Syst. 94:520-527.

Baer, A.G. and C. Brown. 2007. Adoption of e-marketing by direct-market farms in the northeastern U.S. J. Food Distrib. Res. 38(2):1-11.

Ball, T. and Y.L. Duval. 2001. Direct marketing of farm products via the Internet: A survey of smallfarms.com members. 14 Dec. 2018 . <https://www. informatique-agricole.org/download/ efita-conference/Congres_EFITA_ 2001/Ball_96.pdf>.

Barnes, J.N., K. Hood, and R. Gallardo. 2014. The economic impact of social media on small businesses: Evidence from three Mississippi extension programs. 2014 Ann. Mtg. Southern Agr. Econ. Assn., 1-4 Feb. 2014, Dallas, TX. No. 162500 .

Barton, S.S. and B.K. Behe. 2017. Retail promotion and advertising in the green industry: An overview and exploration of the use of digital advertising. HortTechnology 27:99-107.

Behe, B.K., B.L. Campbell, C.R. Hall, H. Khachatryan, J.H. Dennis, and C. Yue. 2013. Smartphone use and online search and purchase behavior of North Americans: Gardening and non-gardening information and products. HortScience 48:200-208.

Bolton, R.A., A. Parasuraman, A. Hoefnagels, N. Migchels, S. Kabadayi, T. Gruber, Y.K. Loureiro, and D. Solnet. 2013. Understanding generation $\mathrm{Y}$ and their use of social media: A review and research agenda. J. Serv. Mgt. 24:245-267.

Boyd, D.M. and N.B. Ellison. 2008. Social network sites: Definition, history and scholarship. J. Comprehensive Media Commun. 13:210-230.

Burt, S. and L. Sparks. 2003. E-commerce and the retail process: A review. J. Retailing Consum. Serv. 10:275-286.

Cameron, A.C. and P.K. Trivedi. 2009. Microeconometrics: Methods and applications. Cambridge Univ. Press, New York, NY.

Danaher, P.J. and T.S. Dagger. 2013. Comparing the relative effectiveness of advertising channels: A case study of a multimedia blitz campaign. J. Mkt. Res. 50:517-534.

Detre, J.D., T.B. Mark, A.K. Mishra, and A. Adhikari. 2011. Linkage between direct marketing and farm income: A double-hurdle approach. Agribusiness 27(1):19-33.

Doctorow, D., R. Hoblit, and A. Sekhar. 2009. Measuring marketing: McKinsey 
global survey results. 3 Mar. 2019. <https:// www.mckinsey.com/business-functions/ marketing-and-sales /our-insights / measuring-marketing-mckinsey-globalsurvey-results $>$.

Duan, N., W.G. Manning, C.N. Morris, and J.P. Newhouse. 1983. A comparison of alternative models for the demand of medical care. J. Bus. Econ. Stat. 1:114126.

Duggan, M., N. Ellison, C. Lampe, A. Lenhart, and M. Madden. 2015. Social media update 2014. Pew Res. Ctr., Washington, DC.

Foehr, U.G. 2006. Media multitasking among American youth: Prevalence, predictors and pairings. 2 Jan. 2019. <https://files.eric.ed.gov/fulltext/ ED527858.pdf $>$.

Gollop, F.M. and J.L. Monahan. 1991. A generalized index of diversification: Trends in U.S. manufacturing. Rev. Econ. Stat. 73:318-330.

Hall, C.R., J.J. Haydu, and A.W. Hodges. 2005. Economic impacts of the green industry in the United States: Final report to the National Urban and Community Forestry Advisory Committee. 3 Mar. 2019. <https://ufei.calpoly.edu/files/ pubs/EconomicImpactsoftheUSGreen\% 20Industr(NUCFACfinalreport).pdf>.

Hall, C.R. 2010. Making cents of green industry economics. HortTechnology 20:832-835

Hodges, A.W., C.R. Hall, M.A. Palma, and H. Khachatryan. 2015. Economic contributions of the green industry in the U.S. in 2013. HortTechnology 25:805814.

Hooker, N.H., J. Heilig, and S. Ernst. 2001. What is unique about E-agribusiness? 2 Jan. 2019. <https:// pdfs.semanticscholar.org/c2 lf/ 9d05364f3117e4c2119c83266d317afa0148. pdf>.

Huang, L.C. and L.C. Chen. 2018. Message strategies and media formats of florists' Facebook posts and their effects on users' engagement behaviors. HortScience 53:1647-1654.

Li, Y., M.A. Palma, C.R. Hall, H. Khachatryan, and O. Capps. Jr. 2019. Measuring the effects of advertising on green industry sales: A generalized propensity score approach. Appl. Econ. 51: 1303-1318.

The Nielsen Co. 2013. The paid social media advertising report. 25 Aug. 2016. <http://www.nielsen.com/us/en/ insights/reports/2013/the-paid-socialmedia-advertising-report-2013.html $>$.

Palma, M.A., C.R. Hall, B. Campbell, H. Khachatryan, B. Behe, and S. Barton. 2012. Measuring the effects of firm promotion expenditures on green industry sales. J. Environ. Hort. 30:83-88.

Perrin, A. 2015. Social media usage. 4 Mar. 2019. <http://www.pewinternet. org $/ 2015 / 10 / 08 / 2015 /$ Social Networking-Usage-2005-2015>.

Peterson, H., C. Boyer, L. Baker, and B. Yao. 2018. Trends in the use of new- media marketing in U.S. ornamental horticulture industries. Horticulturae $4(4): 32$.

Pilotta, J.J., D.E. Schultz, G. Drenik, and P. Rist. 2004. Simultaneous media usage: A critical consumer orientation to media planning. J. Consum. Behav. 3:285-292.

Pookulangara, S. and K. Koesler. 2011. Cultural influence on consumers' usage of social networks and its' impact on online purchase intentions. J. Retailing Consum. Serv. 18:348-354.

Reinartz, W. 1996. The Internet as a marketing tool in ornamental horticulture: An exploratory investigation. Acta Hort. 429:273-278.

Sridhar, S., F. Germann, C. Kang, and R. Grewal. 2016. Relating online, regional, and national advertising to firm value. J. Mktg. 80(4):39-55.

Strauss, J. 2016. E-marketing. Prentice Hall, Upper Saddle River, NJ.

Techopedia. 2018. Online marketing. 13 Mar. 2018. <https://www.techopedia. com/definition / $26363 /$ online marketing $>$.

U.S. Department of Agriculture. 2017. Farm computer usage and ownership. 26 Dec. 2017 . <http://usda.mannlib. cornell.edu/usda/current/FarmComp/ FarmComp-08-18-2017_correction. pdf $>$.

Waters, R.D., E. Burnett, A. Lamm, and J. Lucas. 2009. Engaging stakeholders through social networking: How nonprofit organizations are using Facebook. Public Relat. Rev. 35(2):102-106.

Yao, B., A. Shanoyan, H.H. Peterson, C. Boyer, and L. Baker. 2018. The use of new-media marketing in the green industry: Analysis of social media use and impact on sales. 2 Feb. 2019. <https:// onlinelibrary.wiley.com/doi/full/10. 1002 /agr.21581>. 